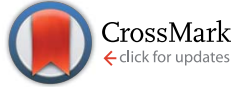

Cite this: J. Mater. Chem. B, 2014, 2, 8427

Received 15th July 2014

Accepted 15th October 2014

DOI: $10.1039 / c 4 t b 01161 a$

www.rsc.org/MaterialsB

\title{
Water-soluble photoluminescent D-mannose and L-alanine functionalized silicon nanocrystals and their application to cancer cell imaging $\dagger$
}

\begin{abstract}
Yi Zhai, ${ }^{a}$ Mita Dasog, ${ }^{a}$ Ryan B. Snitynsky, ${ }^{\text {ab }}$ Tapas K. Purkait, ${ }^{a}$ Maryam Aghajamali, ${ }^{a}$ Allison H. Hahn, ${ }^{c}$ Christopher B. Sturdy, ${ }^{\text {cd }}$ Todd L. Lowary ${ }^{\text {ab }}$ and Jonathan G. C. Veinot ${ }^{\star a e}$

Herein, we report the straightforward synthesis, photoluminescent properties, and cell imaging studies of D-mannose and L-alanine functionalized silicon nanocrystals (SiNCs). Tailoring nanocrystal surface functionalization is essential to interfacing SiNCs with their environment and rendering them stable surface modification also offers the opportunity to target specific cell types for imaging. A simple and versatile surface modification procedure was developed to tether biomolecules onto the SiNC surfaces and render them water-soluble. The presented approach is precious metal-catalyst free, straightforward, and provides carbohydrate and amino acid functionalized SiNCs. The functionalized SiNCs have been investigated by fluorescence microscopy and our results indicate that they can be internalized by MCF-7 human breast cancer cells as shown in the cell imaging studies. The obtained SiNCs were characterized using FTIR, XPS, PL, and TEM.
\end{abstract}

\section{Introduction}

Luminescent quantum dots (QDs) have been proposed as additional type of materials to fluorescent organic dyes for bioimaging applications. ${ }^{1-5}$ Photobleaching is among the most important challenges associated with organic dyes and limits long-term in vitro and in vivo bioimaging. ${ }^{6}$ QDs do not photobleach, exhibit tunable optical properties, ${ }^{1}$ and possess tailorable surface chemistry. ${ }^{7}$ However, II-VI QDs (e.g., CdSe/ZnS QDs) are cytotoxic and hence are of limited practical utility for applications involving biological systems. ${ }^{8-11}$

Silicon nanocrystals (SiNCs) have attracted considerable interest in recent years for biological applications ${ }^{12-16}$ because of their established biocompatibility, ${ }^{17}$ abundance, and tunability. ${ }^{18}$ Because oxidation can change and even quench SiNC photoluminescence (PL), it is crucial that their surfaces be passivated. Unfortunately, protocols typically used to modify IIVI QDs are not readily compatible with SiNCs and alternative methods must be devised. To date, most approaches used to

${ }^{a}$ Department of Chemistry, University of Alberta, Edmonton, Alberta T6G 2G2, Canada.E-mail: jveinot@ualberta.ca

${ }^{b}$ Alberta Glycomics Centre, University of Alberta, Edmonton, Alberta T6G 2G2, Canada 'Department of Psychology, University of Alberta, P217 Biological Sciences Building, Edmonton, AB T6G 2E9, Canada

${ }^{d}$ Centre for Neuroscience, University of Alberta, 513 Heritage Medical Research Centre, Edmonton, AB T6G 2S2, Canada

${ }^{e}$ NRC-National Institute for Nanotechnology, Edmonton, Alberta T6G 2M9, Canada $\dagger$ Electronic supplementary information (ESI) available. See DOI: 10.1039/c4tb01161a modify SiNC surfaces have aimed to introduce long chain alkyl groups rendering NCs hydrophobic and soluble in common organic solvents. Materials modified in this way are typically insoluble in water and their compatibility with biological systems is limited unless further modification is performed (e.g., polymer coating). ${ }^{19}$

Drawing on established approaches for rendering other QDs water-soluble, polar functionalities (e.g., $-\mathrm{NH}_{2}$ and $-\mathrm{COOH}$ ) have been tethered to SiNC surfaces. ${ }^{7,20-22}$ Unfortunately, amine terminated SiNCs are cytotoxic ${ }^{23}$ and carboxylic acid terminated particles can be challenging to prepare and often show weak PL. ${ }^{24}$ In this context, it is useful to explore alternative surface functionalities. Among potential candidates, carbohydrates and amino acids are particularly attractive because these moieties are water-soluble, can be recognized and taken up by cells, and they do not compromise SiNC optical response. While reports describing carbohydrate functionalized SiNCs have appeared, ${ }^{25,26}$ these methods typically involve laborious multi-step procedures, as well as costly and potentially toxic noble metal catalysts ${ }^{27}$ that can compromise SiNC optical response. ${ }^{28}$ To our knowledge, there are no reports of amino acid terminated SiNCs. In this study, we report a straightforward synthetic protocol for preparing water-soluble SiNCs functionalized with D-mannose and L-alanine and demonstrate a prototype application of these particles as luminescent imaging agents for the visualization of MCF-7 human breast cancer cells. 


\section{Experimental}

\section{Materials}

A methyl isobutyl ketone solution of hydrogen silsesquioxane (HSQ) (i.e., FOx® 17) was obtained from Dow Corning. The solvent was removed in vacuo to obtain a white solid that was used without further purification. Electronics grade hydrofluoric acid (HF, 49\%) was purchased from J.T. Baker. Phosphorus pentachloride $\left(\mathrm{PCl}_{5}, 95 \%\right)$, toluene (reagent grade and anhydrous), methanol (reagent grade), ethylene glycol (99.8\%), boron trifluoride diethyl etherate $\left(\mathrm{BF}_{3} \cdot \mathrm{O}\left(\mathrm{C}_{2} \mathrm{H}_{5}\right)_{2}, 46.5 \% \mathrm{BF}_{3}\right)$, azobisisobutyronitrile, and L-alanine methyl ester hydrochloride (99\%) were purchased from Sigma-Aldrich. Sodium methoxide $\left(\mathrm{NaOCH}_{3}, 95 \%\right.$, Fisher), D-mannose (99\%, Alfa Aesar), acetic anhydride (97\%, Caledon Laboratories), pyridine (99\%, Caledon Laboratories), dimethylaminopyridine (DMAP, 98\%, Fluka), 4-pentenoic acid (98\%, Alfa Aesar), and sodium hydroxide ( $\mathrm{NaOH}$, reagent grade, EMD Chemicals) were used as received. DMEM/High glucose medium and gold antifade reagent were purchased from HyClone and Prolong Pharmaceuticals, respectively.

\section{Synthesis of 1,2,3,4,6-penta- $O$-acetyl- $\alpha$-D-mannopyranose}

D-Mannose (2.0 g, $11.1 \mathrm{mmol}$ ) was dissolved in acetic anhydride $(30 \mathrm{~mL})$ at $0{ }^{\circ} \mathrm{C}$. A catalytic quantity of DMAP was added, followed by pyridine $(40 \mathrm{~mL})$. The solution stirred overnight $(16 \mathrm{~h})$ while warming to room temperature. After co-evaporation with toluene $(3 \times 50 \mathrm{~mL})$, the residue was dissolved in ethyl acetate and washed with $1 \mathrm{M} \mathrm{HCl}(2 \times 50 \mathrm{~mL})$, water $(1 \times 50 \mathrm{~mL})$, saturated aqueous $\mathrm{NaHCO}_{3}(2 \times 50 \mathrm{~mL})$, and brine $(1 \times 50 \mathrm{~mL})$. The solution was dried over $\mathrm{Na}_{2} \mathrm{SO}_{4}$, filtered, and concentrated giving a clear, slightly yellow oil. The crude material was purified by column chromatography (silica, $3: 1 \rightarrow 1: 1$ hexane : ethyl acetate) to yield $4.4 \mathrm{~g}(10.7 \mathrm{mmol}, 96 \%)$ of the $\alpha$ anomer of the desired compound as a white solid. The NMR spectrum obtained for the product (Fig. S1†) was consistent with previously published data. ${ }^{29}{ }^{1} \mathrm{H}$ NMR (500 $\left.\mathrm{MHz}, \mathrm{CDCl}_{3}\right) \delta$ 6.09 (d, $J=2.0 \mathrm{~Hz}, 1 \mathrm{H}, \mathrm{H}-1$ ), 5.36-5.34 (m, 2H, H-3, H-4), 5.26 (dd, $J=3.0,2.0 \mathrm{~Hz}, 1 \mathrm{H}, \mathrm{H}-2$ ), 4.28 (dd, $J=12.5,5.0 \mathrm{~Hz}, 1 \mathrm{H}, \mathrm{H}-6$ ), 4.11 (dd, $J=12.5,2.5 \mathrm{~Hz}, 1 \mathrm{H}, \mathrm{H}-6^{\prime}$ ), 4.05 (ddd, $J=9.5,5.0,2.5$ $\mathrm{Hz}, 1 \mathrm{H}, \mathrm{H}-5), 2.18\left(\mathrm{~s}, 3 \mathrm{H}, \mathrm{COCH}_{3}\right), 2.17$ (s, 3H, $\left.\mathrm{COCH}_{3}\right), 2.10$ (s, $\left.3 \mathrm{H}, \mathrm{COCH}_{3}\right), 2.05\left(\mathrm{~s}, 3 \mathrm{H}, \mathrm{COCH}_{3}\right), 2.01\left(\mathrm{~s}, 3 \mathrm{H}, \mathrm{COCH}_{3}\right) ;{ }^{13} \mathrm{C} \mathrm{NMR}$ $\left(125 \mathrm{MHz}, \mathrm{CDCl}_{3}\right) \delta 170.7,170.0,169.8,169.6,168.1(5 \times$ $\mathrm{COCH}_{3}$ ), 90.7 (C-1), 70.7 (C-5), 68.8 (C-3), 68.4 (C-2), 65.6 (C-4), 62.2 (C-6), 20.9, 20.8, 20.8, 20.7, 20.7 (5× $\left.\mathrm{COCH}_{3}\right)$.

\section{Synthesis of 2 '-hydroxyethyl 2,3,4,6-tetra- $O$-acetyl- $\alpha$-D- mannopyranoside (1)}

1,2,3,4,6-Penta- $O$-acetyl- $\alpha$-D-mannopyranose (4.4 g, $10.7 \mathrm{mmol}$ ) and anhydrous ethylene glycol $(3.0 \mathrm{~mL}, 53.5 \mathrm{mmol})$ stirring in dry $\mathrm{CH}_{2} \mathrm{Cl}_{2}(40 \mathrm{~mL})$ under an argon atmosphere were cooled to $0{ }^{\circ} \mathrm{C} . \mathrm{BF}_{3} \cdot \mathrm{OEt}_{2}(6.7 \mathrm{~mL}, 53.5 \mathrm{mmol})$ was added, and the solution gradually warmed to room temperature. After 16 hours, $\mathrm{NaHCO}_{3}$ saturated solution $(40 \mathrm{~mL})$ was added and stirred until gas evolution ceased. The organic layer was separated and washed with $\mathrm{NaHCO}_{3}$ saturated solution $(40 \mathrm{~mL})$ and brine
$(30 \mathrm{~mL})$, then dried over $\mathrm{Na}_{2} \mathrm{SO}_{4}$, filtered, and concentrated to a yellow oil. The crude material was purified by column chromatography (silica, $1: 1$ hexane : ethyl acetate) to yield $1.14 \mathrm{~g}$ of pure material as a colorless oil (2.91 mmol, 27\%). The NMR spectrum obtained on the product (Fig. S2 $\dagger$ ) was consistent with previously published data. ${ }^{30}[\alpha]_{\mathrm{D}}=+40\left(c=0.73, \mathrm{CH}_{2} \mathrm{Cl}_{2}\right)$; FTIR (thin film): 3492, 2941, 2882, 1747, $1232 \mathrm{~cm}^{-1} ;{ }^{1} \mathrm{H}$ NMR (400 $\left.\mathrm{MHz} \mathrm{CDCl}_{3}\right) \delta 5.36(\mathrm{dd}, J=10.4,3.6 \mathrm{~Hz}, 1 \mathrm{H}, \mathrm{H}-3), 5.31-5.24(\mathrm{~m}$, $2 \mathrm{H}, \mathrm{H}-2, \mathrm{H}-4), 4.87$ (d, $J=1.6 \mathrm{~Hz}, 1 \mathrm{H}, \mathrm{H}-1$ ), 4.26 (dd, $J=12.0,5.6$ $\mathrm{Hz}, 1 \mathrm{H}, \mathrm{H}-6$ ), 4.13 (dd, $J=12.0,2.4 \mathrm{~Hz}, 1 \mathrm{H}, \mathrm{H}-6^{\prime}$ ), 4.07 (ddd, $J=$ 10.0, 5.6, 2.4 Hz, 1H, H-5), 3.83-3.65 (m, 4H, OCH $\left.\mathrm{CH}_{2} \mathrm{OH}\right), 2.16$ $\left(\mathrm{s}, 3 \mathrm{H}, \mathrm{COCH}_{3}\right), 2.10\left(\mathrm{~s}, 3 \mathrm{H}, \mathrm{COCH}_{3}\right), 2.05\left(\mathrm{~s}, 3 \mathrm{H}, \mathrm{COCH}_{3}\right), 2.00$ $\left(\mathrm{s}, 3 \mathrm{H}, \mathrm{COCH}_{3}\right) ;{ }^{13} \mathrm{C} \mathrm{NMR}\left(100 \mathrm{MHz}, \mathrm{CDCl}_{3}\right) \delta$ 170.7, 170.1, 170.0, $170.0\left(4 \times \mathrm{COCH}_{3}\right), 98.1(\mathrm{C}-1), 70.6\left(\mathrm{CH}_{2} \mathrm{CH}_{2} \mathrm{OH}\right), 69.6(\mathrm{C}-$ 2), 69.0 (C-3), 68.8 (C-5), 66.3 (C-4), 62.6 (C-6), $61.8\left(\mathrm{CH}_{2} \mathrm{CH}_{2} \mathrm{OH}\right)$, 20.9, 20.8, 20.7, $20.7\left(4 \times \mathrm{COCH}_{3}\right)$; HRMS (ESI) $\mathrm{m} / \mathrm{z}$ calcd for $\mathrm{C}_{16} \mathrm{H}_{24} \mathrm{NaO}_{11}[\mathrm{M}+\mathrm{Na}]+$ : 415.1211. Found: 415.1206.

\section{Synthesis of hydride-terminated SiNCs}

$3.0 \mathrm{~g}$ of HSQ was transferred to a quartz boat and thermally processed under slightly reducing conditions (i.e., flowing 5\% $\mathrm{H}_{2} / 95 \% \mathrm{Ar}$ ) at $1100{ }^{\circ} \mathrm{C}$ for $1 \mathrm{~h}$ in a tube furnace. After the resulting product was cooled to room temperature the amber solid consisting of oxide-embedded SiNCs was ground using an agate mortar and pestle. To obtain freestanding hydrideterminated SiNCs, the ground $\mathrm{SiNC}_{\mathrm{SiO}} \mathrm{S}_{2}$ composite $(0.30 \mathrm{~g})$ was etched using $9 \mathrm{~mL}$ of a $1: 1: 1 / \mathrm{v}: \mathrm{v}: \mathrm{v}$ mixture of $\mathrm{H}_{2} \mathrm{O}$ : ethanol : 49\% HF solution. The mixture was stirred for an hour under ambient conditions to remove the $\mathrm{SiO}_{2}$ matrix. The resulting hydride terminated SiNCs were extracted using three $10 \mathrm{~mL}$ portions of toluene. The product was centrifuged at 3000 rpm for $10 \mathrm{~min}$ and the supernatant was discarded.

\section{Synthesis of chloride-terminated SiNCs}

$\mathrm{PCl}_{5}(0.30 \mathrm{~g}, 1.4 \mathrm{mmol})$ was added to a dry Schlenk flask containing hydride-terminated SiNCs ( $c a .60 \mathrm{mg}$ ) dispersed in toluene $(10 \mathrm{~mL})$ to form a cloudy orange suspension. The resulting mixture was stirred for $1.5 \mathrm{~h}$ under argon atmosphere. Following the reaction the product mixture appeared as a light yellow clear solution. The solvent and reaction byproducts were then removed in vacuo to yield chloride terminated SiNCs (Cl-SiNCs) as an orange solid.

\section{Synthesis of D-mannose functionalized SiNCs}

$1(0.10 \mathrm{~g}, 0.4 \mathrm{mmol})$ was transferred to a Schlenk flask containing Cl-SiNCs (vide supra). $12 \mathrm{~mL}$ of anhydrous toluene were added to the reaction flask. The resulting mixture was stirred for $16 \mathrm{~h}$ at $40{ }^{\circ} \mathrm{C}$ under inert $\mathrm{Ar}$ atmosphere. Subsequently, the toluene was removed from the crude product mixture under vacuum and the resulting particles were dispersed in $10 \mathrm{~mL}$ methanol. Solid sodium methoxide was added to the methanol solution until the $\mathrm{pH} \sim 9$. The resulting solution was stirred in air at ambient temperature for $12 \mathrm{~h}$ and then neutralized using Amberlite IR-120 ion exchange resin (acid form). The neutralization was monitored using $\mathrm{pH}$ paper. The resulting neutral solution was concentrated to yield a solid using a rotary 
evaporator and then functionalized SiNCs were redispersed in water and the exchange resin was removed via gravity filtration.

\section{Synthesis of L-alanine functionalized SiNCs}

L-alanine methyl ester $(0.08 \mathrm{~g}, 0.6 \mathrm{mmol})$ was added to a dry Schlenk flask containing Cl-SiNCs (vide supra). $12 \mathrm{~mL}$ dry toluene were added to the reaction flask and the resulting mixture was stirred for $16 \mathrm{~h}$ at $40{ }^{\circ} \mathrm{C}$ under inert Ar atmosphere. Following the reaction the solvent was removed using a rotary evaporator. The resulting solid residue was redispersed in $5 \mathrm{~mL}$ of methanol. $2.5 \mathrm{~mL}$ of $1 \mathrm{M}$ aqueous $\mathrm{NaOH}$ were added to the alanine methyl ester functionalized SiNCs. The solution was then heated to reflux and stirred for 1 hour followed by cooling to room temperature. The resulting solution was neutralized using Amberlite IR-120 ion exchange resin (acid form), and the neutralization process was monitored using $\mathrm{pH}$ paper. The solution was concentrated to yield a solid using rotary evaporator. The SiNCs were redispersed in water and the exchange resin was removed via gravity filtration.

\section{Synthesis of pentanoic acid functionalized SiNCs}

Immediately after etching $0.2 \mathrm{~g}$ of $\mathrm{SiNC} / \mathrm{SiO}_{2}$ composite, the resulting hydride-terminated SiNCs were isolated and redispersed in $15 \mathrm{~mL}$ dry toluene in a Schlenk flask equipped with a stir bar. Azobisisobutyronitrile (AIBN, $10 \mathrm{mg}$ ) and 4-pentenoic acid ( $4 \mathrm{~mL}$ ) were added to the flask and the mixture degassed by performing three freeze/pump/thaw cycles using an Ar charged Schlenk line. The solution was stirred at $65{ }^{\circ} \mathrm{C}$ for $15 \mathrm{~h}$ after which time the reaction mixture was transferred into test tubes and centrifuged at $3000 \mathrm{rpm}$. The supernatant was discarded and the solid product was purified by three successive dispersion/precipitation cycles by the addition of ethanol/pentane mixture as the solvent/antisolvent and centrifugation.

\section{Cell studies}

$10 \mu \mathrm{L}$ of the solution of mannose functionalized SiNCs $(620 \mu \mathrm{g}$ $\mathrm{mL}^{-1}$ ) were added to $300 \mu \mathrm{L}$ medium containing MCF-7 cells (6000 cells per well). The same concentration of solutions of alanine and pentanoic acid functionalized SiNCs were prepared and added to MCF-7 cells respectively. The cells were incubated at $37^{\circ} \mathrm{C}$ for 24 hours. Subsequently, the medium was removed upon washing with phosphate buffered saline (PBS). Cells were "fixed" upon incubation with paraformaldehyde for 30 minutes. Fixed cells were washed with PBS three times and a small drop of anti-fade solution was added to each slide. A coverslip was placed over the specimen and the edges were sealed with clear nail polish.

\section{Characterization}

Fourier Transformation Infrared Spectroscopy (FT-IR) was performed using a Nicolet Magna 750 IR spectrometer. Photoluminescence (PL) spectra of solution samples were acquired using a Varian Cary Eclipse Fluorescence Spectrometer. High resolution (HR) TEM images were obtained from Hitachi-9500 electron microscope with an accelerating voltage of $300 \mathrm{kV}$.
TEM samples were prepared by dropcoating freestanding SiNC suspensions onto a holey carbon coated copper grid and the solvent was removed under vacuum. The NC size was averaged for 200 particles using Image J software (version 1.45). The HRTEM images were processed using Gatan Digital Micrograph software (Version 2.02.800.0).

X-ray photoelectron spectroscopy (XPS) analyses were performed using a Kratos Axis Ultra instrument operating in energy spectrum mode at $210 \mathrm{~W}$. Samples were prepared as films dropcast from solution onto a copper foil substrate. The base and operating chamber pressure were maintained at $10^{-7} \mathrm{~Pa}$. A monochromatic $\mathrm{Al} \mathrm{K}_{\alpha}$ source $(\lambda=8.34 \AA)$ was used to irradiate the samples, and the spectra were obtained with an electron take-off angle of $90^{\circ}$. To minimize sample charging, the charge neutralizer filament was used when required. Survey spectra were collected using an elliptical spot with major and minor axis lengths of 2 and $1 \mathrm{~mm}$, respectively, and $160 \mathrm{eV}$ pass energy with a step of $0.33 \mathrm{eV}$. CasaXPS software (VAMAS) was used to interpret high-resolution (HR) spectra. All spectra were internally calibrated to the $\mathrm{C} 1 \mathrm{~s}$ emission $(284.8 \mathrm{eV})$. After calibration, a Shirley-type background was applied to remove most of the extrinsic loss structure. The FWHM for all the fitted peaks was maintained below $1.2 \mathrm{eV}$.

Relative photoluminescent quantum yields were determined using methods adapted from the work of Williams et $a .^{31}$ Cyclohexane solutions of 9,10-biphenylanthracene and absolute ethanol solutions of coumarin 1 were used as fluorescent standards. Functionalized Si-NCs were dissolved in methanol. All organic solvents were passed through a column of anhydrous magnesium sulfate to remove residual moisture immediately prior to solution preparation. Stock solutions were prepared by dissolving $10 \mathrm{mg}$ of the organic dye in the appropriate solvent. Solutions were subsequently filtered through a membrane filter to remove suspended impurities. A series of solutions with absorbances within the range of 0.01 to 0.1 were prepared. PL spectra were acquired for the identical solutions upon excitation at $300 \mathrm{~nm}$. The slopes of plots of the integrated fluorescence intensity vs. UV-Vis absorbance intensity curves determined and compared to confirm the quality of the reference curves. In all cases, the experimentally determined quantum yields were in good agreement with literature values: 9,10-biphenylanthracene, 0.9 and coumarin 1, 0.73. The PL spectra of Si-NC solutions and reference samples were acquired under identical conditions. The quantum yields were determined using the following equation:

$$
\varphi_{x}=\varphi_{\mathrm{st}}\left(\frac{m_{x}}{m_{\mathrm{st}}}\right)\left(\frac{\eta_{x}{ }^{2}}{\eta_{\mathrm{st}}{ }^{2}}\right)
$$

where ' $\varphi$ ' is the quantum yield, ' $m$ ' is the slope of the integrated PL versus absorbance curve and ' $\eta$ ' is the refractive index of the solvent. The subscript 'st' refers to the standard organic dye while ' $x$ ' indicates the unknown species to be calculated.

Dynamic Light Scattering (DLS) measurements were performed using a Malvern Zetasizer Nano S equipped with a 633 $\mathrm{nm}$ laser. All samples were filtered using a $0.45 \mu \mathrm{m}$ PTFE syringe filter and equilibrated to $25{ }^{\circ} \mathrm{C}$ prior to data acquisition. A refractive index of 1.460 used for all measurements. 
Cell imaging was performed using a Leica microscope (DM5500B; Wetzlar, Germany) with a $20 \times$ objective and a Retiga Exi camera (Qimaging, Surrey, BC, Canada) using Openlab 5.1 (Perkin Elmer Inc., Waltham, MA, USA).

\section{Results and discussion}

\section{SiNCs synthesis and surface functionalization}

Our group has previously reported the preparation of oxideembedded and freestanding SiNCs from the reductive thermal processing of HSQ. ${ }^{24}$ This procedure affords well-defined, comprehensively characterized materials with dimensions that depend upon the processing conditions. ${ }^{32,33}$ Chloride terminated SiNCs (Cl-SiNCs) are obtained upon reaction of hydride terminated SiNCs with phosphorus pentachloride $\left(\mathrm{PCl}_{5}\right){ }^{34,35}$ Reaction byproducts and toluene are readily removed from the $\mathrm{Cl}-\mathrm{SiNCs}$ in vacuo. However, isolation and direct characterization of these particles was impractical given their reactivity. It is these Cl-terminated NCs that were used as the functionalization platform for the present study. Further derivatization of
Cl-SiNCs (Scheme 1) was achieved upon direct addition of acetate-protected D-mannose or L-alanine methyl ester hydrochloride followed by neutralization and appropriate deprotection. The resulting functionalized SiNCs were dispersed in water.

\section{Nanocrystal characterization}

FTIR spectroscopy provides valuable insight into the nature of the SiNC surface chemistry (Fig. 1 and S6†). As expected, the FTIR spectrum of hydride terminated SiNCs (not shown) reveals a characteristic $\mathrm{Si}-\mathrm{H}$ stretching feature at $2100 \mathrm{~cm}^{-1} .^{32}$ The reactivity of $\mathrm{Cl}-\mathrm{SiNCs}$ precluded isolation and direct characterization; however, comprehensive characterization (vide infra) of the products isolated from subsequent derivatization procedures confirm the NC integrity was not compromised by exposure to $\mathrm{PCl}_{5}$.

Functionalization with an acetate-protected D-mannosederived glycoside, L-alanine methyl ester, and pentanoic acid yielded SiNCs displaying FTIR spectra with features characteristic of the target surface groups (see Fig. 1 and S6†). Among the

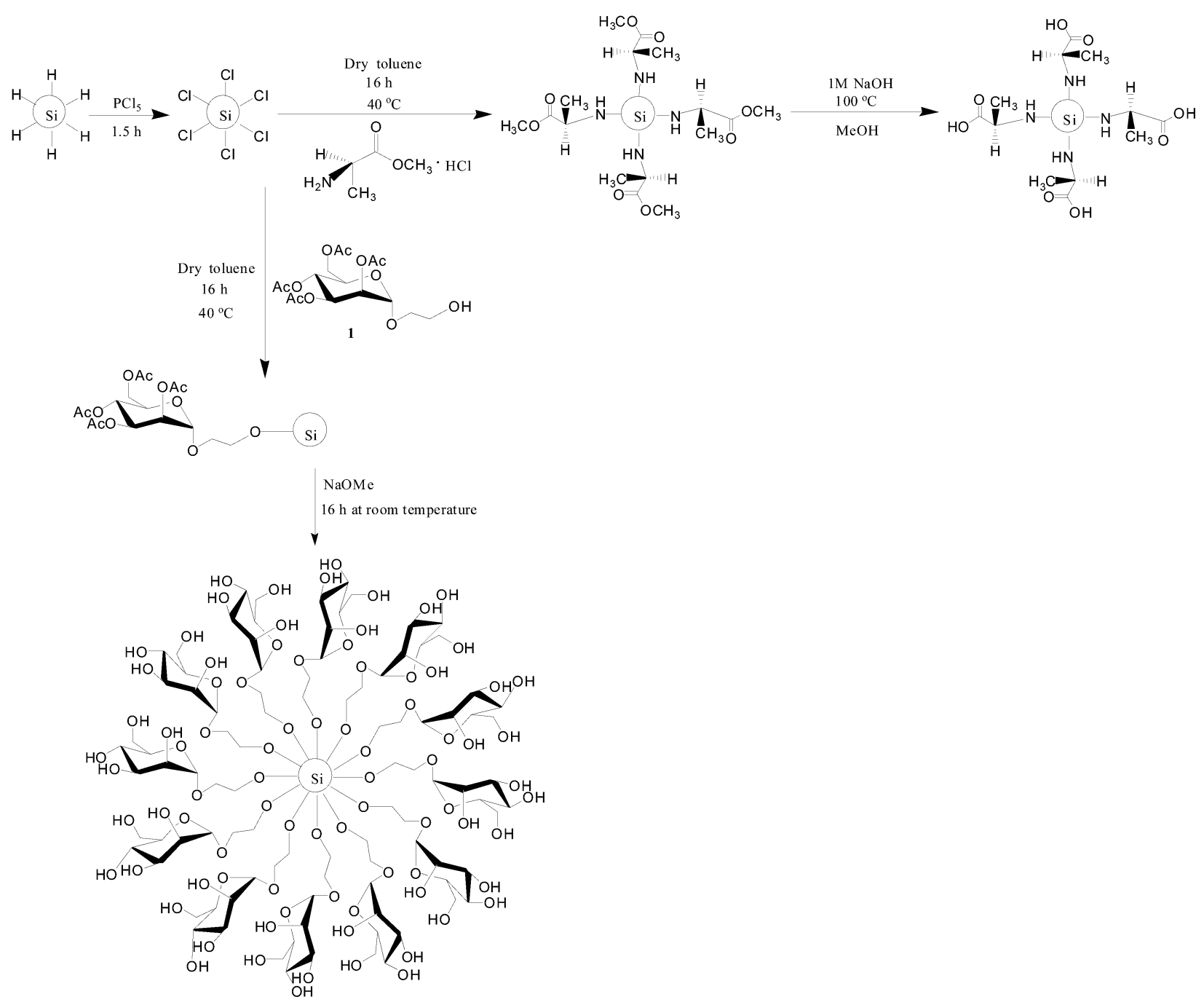

Scheme 1 Chlorination of hydride-terminated SiNCs and the synthesis of mannose and alanine functionalized SiNCs. 

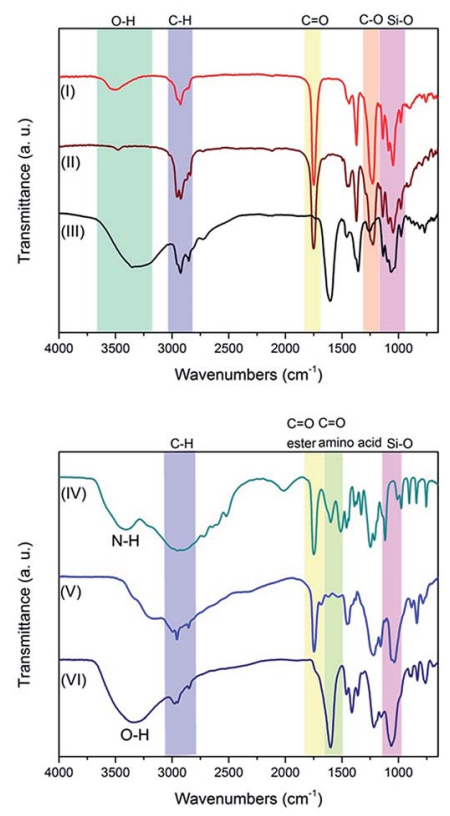

Fig. 1 FTIR spectra of (I) 1, (II) 1 functionalized SiNCs, (III) mannose functionalized SiNCs, (IV) L-alanine methyl ester hydrochloride, (V) alanine methyl ester functionalized SiNCs, and (VI) alanine functionalized SiNCs.

most dominant features in both spectra is an absorption at $c a$. $1735 \mathrm{~cm}^{-1}$ that is readily attributed to $\mathrm{C}=\mathrm{O}$ stretching arising from the ester functionalities. Following deprotection of the $\mathrm{D}^{-}$ mannose SiNCs the $\mathrm{C}=\mathrm{O}$ feature was replaced by a broad absorption centred at $3350 \mathrm{~cm}^{-1}$ consistent with the presence of -OH moieties. A comparison of the spectra obtained before and after deprotection of the alanine methyl ester functionalized SiNCs revealed similar changes.

Among the attractive properties of the present SiNCs that can be applied to biological imaging is their PL response. SiNC PL can be influenced by surface chemistry although the exact origin of the luminescence remains the subject of much investigation. ${ }^{34-38}$ Aqueous solutions of the presented mannose and alanine functionalized SiNCs show blue PL with maximum ca. $415 \mathrm{~nm}$ and $400 \mathrm{~nm}$ upon excitation at $350 \mathrm{~nm}$ (Fig. 2). The PL spectrum of an aqueous solution of pentanoic acid

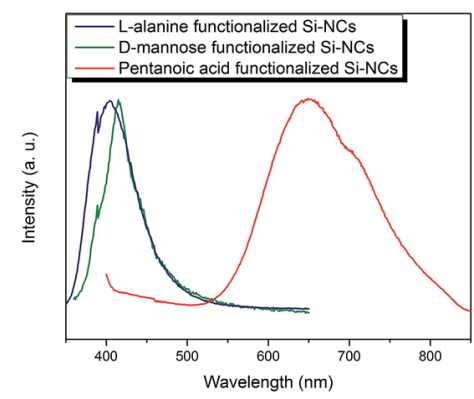

Fig. 2 PL spectra of mannose functionalized SiNCs excited at $350 \mathrm{~nm}$, alanine functionalized SiNCs excited at $335 \mathrm{~nm}$, and pentanoic acid functionalized SiNCs excited at $350 \mathrm{~nm}$. functionalized SiNCs shows a maximum at $c a .640 \mathrm{~nm}$ upon excitation at $350 \mathrm{~nm}$. Photoluminescent quantum yields of mannose and alanine functionalized SiNCs have been investigated. The quantum yield of mannose functionalized SiNCs is $13 \%$ and of alanine functionalized SiNCs is $17 \%$.

XPS provides information regarding the elemental composition of the functionalized SiNCs, insight into the degree of surface oxidation, and confirmation that the SiNC core remains intact. Survey XP spectra of the presented NCs (Fig. S5†) showed expected elemental emission features. The emissions at 102.2 eV (Fig. 3A), $102.1 \mathrm{eV}$ (Fig. 3B), and $100.3 \mathrm{eV}$ (Fig. 3C) can be attributed to $\mathrm{Si}-\mathrm{O}, \mathrm{Si}-\mathrm{N}$ and $\mathrm{Si}-\mathrm{C}$ functionalities, respectively. ${ }^{35}$ The emission feature at lower binding energy (i.e., ca. $99.3 \mathrm{eV}$ ) confirms the presence of a $\mathrm{Si}(0)$ core in each sample. The $\mathrm{N} 1 \mathrm{~s}$ peak (Fig. 3D) is consistent with the presence of alanine on the particle surface.

HRTEM imaging (Fig. 4) further confirms the SiNCs crystalline core remains intact. Lattice fringes spaced by $0.33 \mathrm{~nm}$, characteristic of (111) separation, ${ }^{39}$ are noted for D-mannose, $\mathrm{L}^{-}$ alanine and pentanoic acid particles. TEM images (Fig. 5) also show mannose functionalized SiNCs with diameters of $2.6 \pm 0.6$ $\mathrm{nm}$ and alanine functionalized SiNCs with diameters of $2.7 \pm$ $0.5 \mathrm{~nm}$. Particle size distributions are shown in Fig. S3. $\dagger$ DLS measurements (Fig. S4†) show mannose functionalized SiNCs with hydrodynamic diameters of $87.3 \mathrm{~nm}$, alanine functionalized SiNCs with hydrodynamic diameters of $87.3 \mathrm{~nm}$ and pentanoic acid functionalized SiNCs with hydrodynamic diameters of $72.0 \mathrm{~nm}$.

\section{Cell study}

All three surface modifications chosen for the present study rendered SiNCs water-soluble and compatible with cell media. Previously D-mannose surface functionalities proved effective in the targeted imaging of MCF-7 breast cancer cells; ${ }^{25}$ alanine and pentanoic acid were chosen for their structural simplicity. MCF-
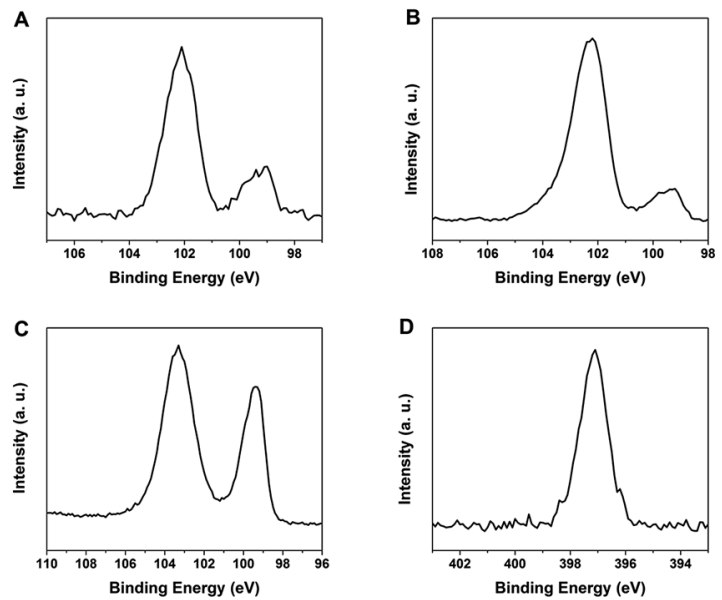

Fig. 3 X-ray photoelectron spectra (XPS) of the (A) Si 2p spectral region of mannose functionalized SiNCs, (B) Si $2 p$ spectral region of alanine functionalized SiNCs, (C) Si $2 p$ spectral region of pentanoic acid functionalized SiNCs, and (D) N 1s spectral region of alanine functionalized SiNCs. 

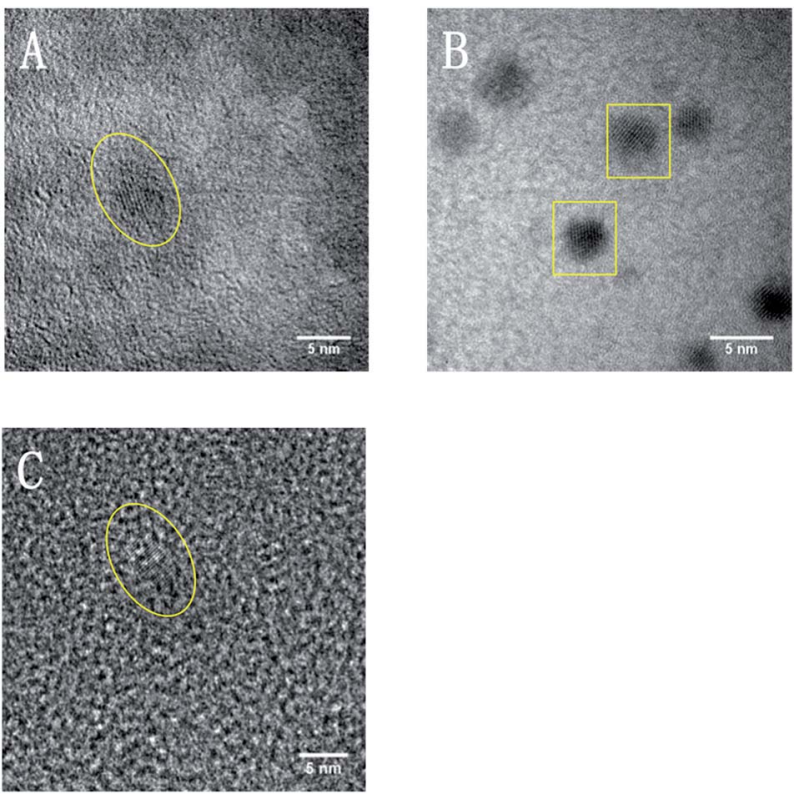

Fig. 4 HRTEM images of (A) mannose functionalized SiNCs, (B) alanine functionalized SiNCs, and (C) pentanoic acid functionalized SiNCs.
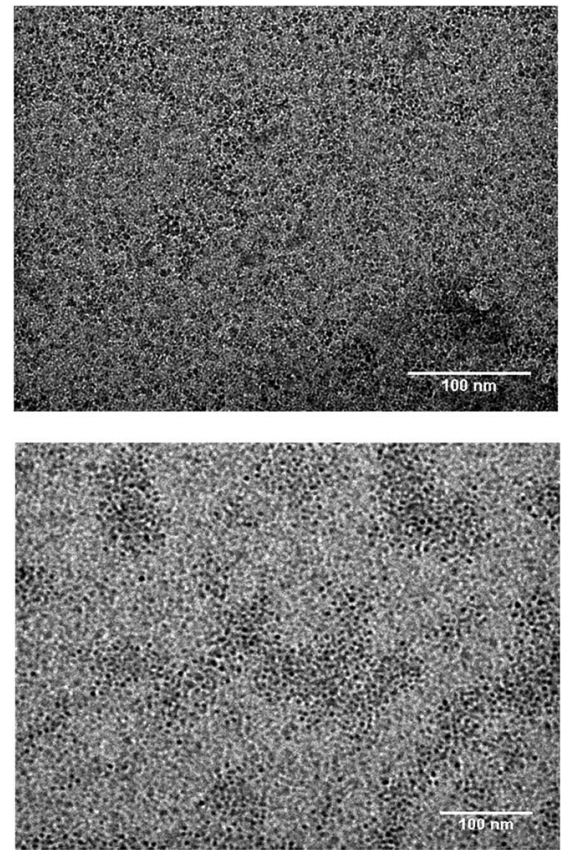

Fig. 5 TEM images of mannose functionalized SiNCs (top), and alanine functionalized SiNCs (bottom).

7 human breast cancer cells are an epithelial human cell line that grows quickly and easily and offers a convenient test imaging system. The uptake of mannose (Fig. 6B) and alanine (Fig. 6D) functionalized SiNCs by MCF-7 breast cancer cells was observed. To investigate if particle uptake resulted from the mannose or alanine functionalization, and not straightforward water solubility, cells were exposed to water-soluble red photoluminescent pentanoic acid functionalized SiNCs (see Fig. S6
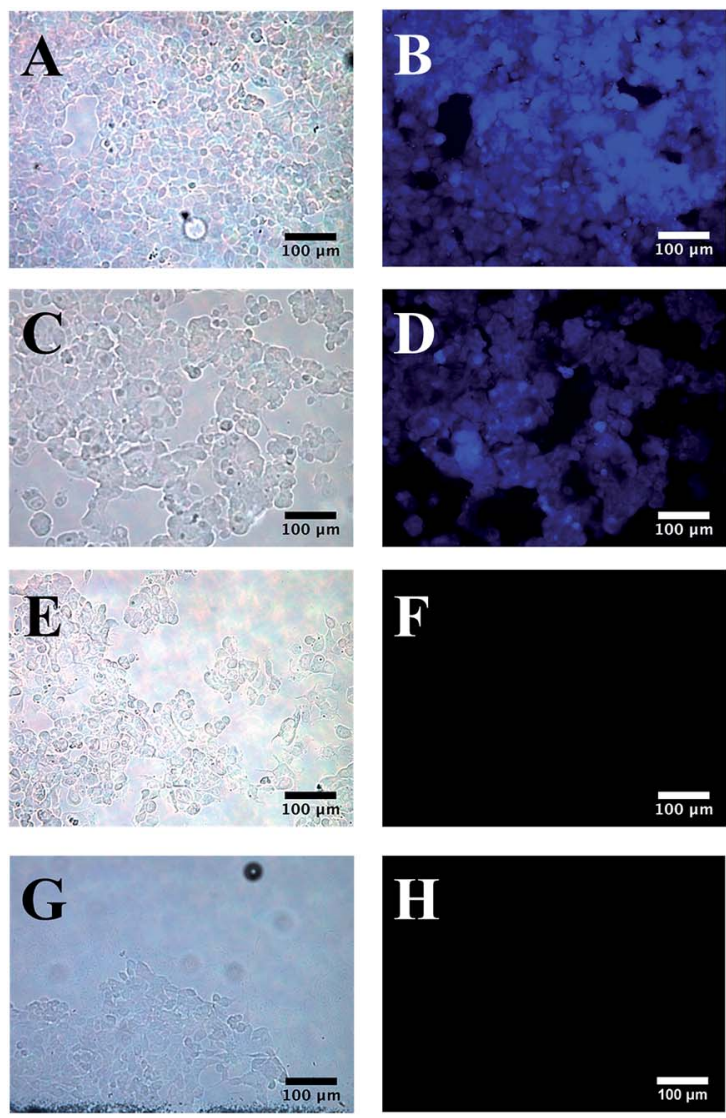

Fig. 6 Images of MCF-7 cancer cells: with (B) and without (A) fluorescence from mannose functionalized SiNCs; with (D) and without (C) fluorescence from alanine functionalized SiNCs; with (F) and without (E) fluorescence from control (without SiNCs), and with $(H)$ and without (G) fluorescence from control (pentanoic acid functionalized SiNCs).

and $\mathrm{S} 7 \dagger$ for detailed characterization). No uptake of pentanoic acid functionalized SiNCs by the MCF-7 breast cancer cell was observed. These observations support the conclusion that mannose and alanine functionalization promoted cell uptake.

\section{Conclusions}

In this work, we have demonstrated the synthesis and characterization of water-soluble, photoluminescent functionalized SiNCs bearing D-mannose, L-alanine, or pentanoic acid. These particles were subsequently visualized in MCF-7 human breast cancer cells. Mannose and alanine functionalized SiNCs were found to be taken up by MCF-7 cells allowing imaging; however, the pentanoic acid terminated SiNC did not. This observation indicates SiNCs can be effective luminescent imaging agents and that appropriate surface chemistry is crucial to their effectiveness in this application.

\section{Acknowledgements}

The authors acknowledge funding from the Natural Sciences and Engineering Research Council of Canada (NSERC), Canada 
Foundation for Innovation (CFI), Alberta Science and Research Investment Program (ASRIP), Alberta Ingenuity Fund (AIF) New Faculty Grant, New Opportunities Fund (NOF), Infrastructure Operating Fund (IOF), CFI partner funding from the University of Alberta, Alberta Innovates Technology Futures (AITF), Alberta Glycomics Centre, and University of Alberta Department of Chemistry. We would like to express our appreciation to Gareth Lambkin for assistance with the cell growth experiments. We would also like to thank Brett Mason and Wayne Moffat for assistance with FT-IR spectroscopy, the staff at the Alberta Centre for Surface Engineering and Sciences (ACSES) for XPS analysis and Kai Cui at National Institute of Nanotechnology (NINT) for TEM analysis. All Veinot Team members are thanked for useful discussions.

\section{Notes and references}

1 X. Michalet, F. F. Pinaud, L. A. Bentolila, J. M. Tsay, S. Doose, J. J. Li, G. Sundaresan, A. M. Wu, S. S. Gambhir and S. Weiss, Science, 2005, 307, 538.

2 Y. He, C. Fan and S. T. Lee, Nano Today, 2010, 5, 282.

3 M. Bruchez Jr, M. Moronne, P. Gin, S. Weiss and A. P. Alivisatos, Science, 1998, 281, 2013.

4 W. C. W. Chan, D. J. Maxwell, X. Gao, R. E. Bailey, M. Han and S. Nie, Curr. Opin. Biotechnol., 2002, 13, 40.

5 C. M. Niemeyer, Angew. Chem., Int. Ed., 2001, 40, 4128.

6 U. Resch-Genger, M. Grabolle, S. Cavaliere-Jaricot, R. Nitschke and T. Nann, Nat. Methods, 2008, 5, 763.

7 M. De, S. Ghosh and V. M. Rotello, Adv. Mater., 2008, 20, 4225.

8 Y. Su, M. Hu, C. Fan, Y. He, Q. Li, W. Li, L. Wang, P. Shen and Q. Huang, Biomaterials, 2010, 31, 4829.

9 T. S. Hauck, R. E. Anderson, H. C. Fischer, S. Newbigging and W. C. W. Chan, Small, 2010, 6, 138.

10 A. M. Derfus, W. C. W. Chan and S. N. Bhatia, Nano Lett., 2004, 4, 11.

11 R. Hardman, Environ. Health Perspect., 2006, 114, 165.

12 Z. Kang, Y. Liu and S. T. Lee, Nanoscale, 2011, 3, 777.

13 F. Erogbogbo, K. T. Yong, I. Roy, R. Hu, W. C. Law, W. Zhao, H. Ding, F. Wu, R. Kumar, M. T. Swihart and P. N. Prasad, ACS Nano, 2011, 5, 413.

14 J. Liu, F. Erogbogbo, K. T. Yong, L. Ye, J. Liu, R. Hu, H. Chen, Y. Hu, Y. Yang, J. Yang, I. Roy, N. A. Karker, M. T. Swihart and P. N. Prasad, ACS Nano, 2013, 7, 7303.

15 F. Erogbogbo, C. W. Chang, J. L. May, L. Liu, R. Kumar, W. C. Law, H. Ding, K. T. Yong, I. Roy, M. Sheshadri, M. T. Swihart and P. N. Prasad, Nanoscale, 2012, 4, 5483.

16 E. Borsella, R. D'Amato, M. Falconieri, E. Trave, A. Panariti and I. Rivolta, J. Mater. Res., 2013, 28, 193.

17 J. Park, L. Gu, G. V. Maltzahn, E. Ruoslahti, S. N. Bhatia and M. J. Sailor, Nat. Mater., 2009, 8, 331.
18 J. A. Kelly, A. M. Shukaliak, M. D. Fleischauer and J. G. C. Veinot, J. Am. Chem. Soc., 2011, 133, 9564.

19 C. M. Hessel, M. R. Rasch, J. L. Hueso, B. W. Goodfellow, V. A. Akhavan, P. Puvanakrishnan, J. W. Tunnel and B. A. Korgel, Small, 2010, 6, 2026.

20 N. Prtljaga, E. D'Amato, A. Pitanti, R. Guider, E. Froner, S. Larcheri, M. Scarpa and L. Pavesi, Nanotechnology, 2011, 22, 215704.

21 Y. He, Y. Zhong, F. Peng, X. Wei, Y. Sun, Y. Lu, S. Su, W. Gu, L. Liao and S. T. Lee, J. Am. Chem. Soc., 2011, 133, 14192.

22 F. Erogbogbo, C. A. Tien, C. W. Chang, K. T. Yong, W. C. Law, H. Ding, I. Roy, M. T. Swihart and P. N. Prasad, Bioconjugate Chem., 2011, 22, 1081.

23 L. Ruizendaal, S. Bhattacharjee, K. Pournazari, M. Rossovasic, L. H. J. De Haan, G. M. Alink, A. T. M. Marcelis and H. Zuihof, Nanotoxicology, 2009, 3, 339.

24 R. J. Clark, M. K. M. Dang and J. G. C. Veinot, Langmuir, 2010, 26, 15657.

25 J. H. Ahire, I. Chambrier, A. Mueller, Y. Bao and Y. Chao, ACS Appl. Mater. Interfaces, 2013, 5, 7384.

26 Y. Nakahara, K. Machiya, T. Sato, N. T. New, T. Furuike, H. Tamura and K. Kimura, Chem. Lett., 2013, 42, 498.

27 J. M. Lambert, J. Biomed. Mater. Res., Part B, 2006, 78, 167.

28 Z. Yang, M. H. Wahl and J. G. C. Veinot, Can. J. Chem., 2014, 92, 1.

29 M. Dowlut, D. G. Hall and O. Hindsgaul, J. Org. Chem., 2005, 70, 9809.

30 W. Hayes, H. M. I. Osborn, S. D. Osborne, R. A. Rastall and B. Romagnoli, Tetrahedron, 2003, 59, 7983.

31 A. T. R. Williams, S. A. Winfield and J. N. Miller, Analyst, 1983, 108, 1067.

32 C. M. Hessel, E. J. Henderson and J. G. C. Veinot, Chem. Mater., 2006, 18, 6139.

33 Z. Yang, A. R. Dobbie, K. Cui and J. G. C. Veinot, J. Am. Chem. Soc., 2012, 134, 13958.

34 M. Dasog and J. G. C. Veinot, Phys. Status Solidi A, 2012, 209, 1844.

35 M. Dasog, G. B. De los Reyes, L. V. Titova, F. A. Hegmann and J. G. C. Veinot, ACS Nano, 2014, 8, 9636.

36 M. Dasog, Z. Yang, S. Regli, T. M. Atkins, A. Faramus, M. P. Singh, E. Muthuswamy, S. M. Kauzlarich, R. D. Tilley and J. G. C. Veinot, ACS Nano, 2013, 7, 2676.

37 S. S. Nekrashevich and V. A. Gritsenko, J. Appl. Phys., 2011, 110, 114103.

38 J. Fuzell, A. Thibert, T. M. Atkins, M. Dasog, E. Busby, J. G. C. Veinot, S. M. Kauzlarich and D. S. Larsen, J. Phys. Chem. Lett., 2013, 4, 3806.

39 S. Liu, M. Kobayashi, S. Sato and K. Kimura, Chem. Commun., 2005, 4690. 